\title{
Correlative analysis of blood pressure and other biochemical parameters with type 2 DM subjects
}

\author{
J Ferdous', R Laila ${ }^{2}$, S Ahmed ${ }^{3}$, N Begum ${ }^{4}$, I A Begum ${ }^{5}$, M Sen ${ }^{6}$, A K M Yousuf ${ }^{7}$, S Ferdousi ${ }^{8}$
}

1 Dr. Jannatul Ferdous Assistant Professor Dept. of Biochemistry

Dr. Runa Laila

Assistant Professor

Dept. of Pharmacology

Shahabuddin Medical College

and Hospital

3 Dr. Shamim Ahmed

Assistant Professor

Dept. of Respiratory

Medicine, BSMMU

4

Dr. Nasreen Begum

Assistant Professor

Dept. of community Medicine

${ }^{5}$ Dr. Ismat Ara Begum

Associate Professor

Dept. of biochemistry

Popular medical college

6 Dr. Moushumi Sen

Associate Professor

Dept. of biochemistry

Anwer Khan Modern Medical College

${ }^{7}$ Dr. Abul Kalam Mohammad Yousuf Assistant Professor

Dept. of Pharmacology

8 Dr. Sohani Ferdousi

Medical officer

Dept. of Biochemistry

National institute of Kidney

diseases \& Urology

\section{$1,4,7$}

Northern International Medical College

\section{Correspondence}

Dr. Jannatul Ferdous

Assistant Professor

Dept. of biochemistry

Northern International Medical College

Email: jannatulshipra@gmail.com
Objective : To determine the association of blood pressure and other biochemical parameters with type $2 \mathrm{DM}$ subjects.

Methodology : This was an observational study with case control design was conducted in the Biomedical Research Group, Research Division, Bangladesh Institute of Research and Rehabilitation in Diabetes ,Endocrine Metabolic Disorders (BIRDEM), Dhaka Bangladesh, during the period of July 2008 to June 2009. A total of 153 subjects were included in study of which 63 belonged to T2 Diabetes Mellitus group and 90 were healthy Controls. Insulin glucose ratio were assayed in patients and controls and identified the association, using standardized assay methods. We also assessed the type - 2 diabetic patients who had significantly raised Fasting blood sugar, insulin HOMA-B $\%=$ B cell function assessed by homeostasis model assessment to compared with the healthy controls. Correlation analysis of HOMA-B \% with biochemical parameters, blood pressure, fasting and post prandial glucose also analysed.

Results : Age of Control and type $2 \mathrm{DM}$ subjects ( Mean $\pm S D$ ),P-value] were $(46 \pm 8.31)$ and $(47 \pm 7.58),(P=0.326)$ respectively and $\mathrm{BMI}$, among subject and control $\left(\mathrm{kg} / \mathrm{m}^{2)}\right.$, (Mean $\left.\pm \mathrm{SD}\right),(24 \pm 3.96,25 \pm$ $2.72 \mathrm{p}=0.754)$. WHR $\left[\mathrm{cm},\left(\mathrm{Mean}_{ \pm} \mathrm{SD}\right), \mathrm{p}=<0.001\right]$, showed significant difference between T2 DM and healthy subjects. The median (range) of the glucose and insulin ratio of the study group, there was significant difference between Control vs. T2DM $(p<0.001)$. Systolic blood pressure[S-BP, mean $\pm S D] \&$ Diastolic blood pressure $[D-B P$, mean $\pm S D]$ were significant in $T 2 D M$ as compared to control subjects $\{(p=0.008)(p=0.003)\}$ respectively ; Fasting plasma glucose levels [mmol/l, (Mean $\pm S D)]$, post prandial plasma glucose level [mmolll, (Mean \pm SD)] and the HOMA\%B level median (range) among subject and control of the study group $[(8.27 \pm 2.19),(11.79 \pm 2.69),\{71$ ( $4.90 \cdot 391.30)\}]$ were a significant difference in between Control vs type2 DM $\{(\mathrm{p}<0.001)$, $(p<0.001)$ and. $(p<0.001)\}$ respectively.

Conclusion : In this study, boty systolic and diastolic blood pressure, blood glucose level and insulin status and WHR were found the significant parameters for maintaining type to DM under control condition. Development of hypertension cardio vascular disease and other complication can be prevented on keeping these parameters in normal level.

Key words : Glucose insulin ratio, Type 2 DM ,BMI, Hypertension, WHR.

\section{Introduction}

Type -2 diabetes mellitus, one of the top five causes for mortality, affected more than 170 million individuals worldwide. ${ }^{1}$ More than $80 \%$ of the deaths in diabetic subjects are attributed to Cardiovascular diseases. ${ }^{2}$ Essential hypertension is common and is an important risk factor for coronary heart disease, stroke, atherosclerosis and peripheral vascular disease $^{3}$. There is a substantial evidence to say that the prevalence of hypertension in diabetics is twice as common as compared to non-diabetics ${ }^{4}$. Both hypertension and diabetes predisposes to the development of cardiovascular diseases (CVD) ${ }^{5}$. When hypertension coexists with diabetes, the risk of CVD is elevated by $75 \%$, which further contributes to the overall morbidity and mortality of an already high risk population ${ }^{6}$, Hypertension in Type-2 diabetic patients clusters with other CVD risk factors such as microalbuminuria, central obesity, insulin resistance, dyslipidaemia, hypercoagulation, increased inflammation and left ventricular hypertrophy?. This clustering of risk factors in diabetic patients ultimately results in the development of CVD, which is the major cause of premature mortality in these patients. Studies of hypertension control in diabetes show a clear and consistent effect: Improved control of blood pressure leads to substantially reduced risks for cardiovascular events and death ${ }^{8}$ Over the last few decades there has been increasing interest in the clinical association between hypertension and diabetes $^{9}$. A Moroccan representative sample aged 20 years old conducted during the year 2000, on cardiovascular risk factors showed that the prevalence of diabetes was $6.6 \%$, the prevalence of hypertension was $33.6 \%$ (30.2\% for men and $37.0 \%$ for women) and the prevalence of cardiovascular risk factors was high within the Moroccan population ${ }^{10}$

Very recently, the results of the ACCORD (Action to Control Cardiovascular Risk in Diabetes) trial, which randomized people with diabetes to a target systolic $B P$ value of either less than $140 \mathrm{~mm} \mathrm{Hg}$ or less than $120 \mathrm{~mm} \mathrm{Hg}$, were published. ${ }^{11}$

Hyperinsulinemia is in - itself an independent cause of atherosclerosis as it promotes atherogenic dyslipidaemia ${ }^{12}$ that enhanced CVD risk in such individuals. There are reports of increased risk of hypertension in type2 diabetic subjects with deteriorating glycaemic control ${ }^{13}$.

The strategy adopted in this study is to explore the effect of the anthropometric and biochemical confounders on insulin secretory defect in T2DM.

\section{Methods}

This was a observational study with case control design. A total of 63 type 2 DM patients and 90 healthy controls were studied between 30-60 years of age Subjects were selected from the Out-Patient 
Department (OPD) of BIRDEM who came for checking their glycemic status during the period of July 2008 to June 2009. Their height, weight and systolic and diastolic blood pressures were recorded.

This study was conducted to assess glucose insulin ratio and blood pressure among the normal to overweight BMI in healthy control group and insulin resistance type 2 DM subjects. The statistical significance of differences between the values was assessed by ' $t$ ' test. A two-tailed $p$ value of $<0.05$ was considered statistically significant.

Results of Anthropometric and Clinical characteristics of the study subjects were expressed as Mean $\pm \mathrm{SD}, \mathrm{T}$ test was performed as the test of significance at $5 \%$ significance level. $n=$ number of subjects, $\mathrm{BMI}=$ Body mass index, WHR=Waist hip ratio, $\mathrm{S} \_\mathrm{BP}=$ Systolic blood pressure and D_BP= Diastolic blood pressure, Glu:Ins= Glucose Insulin ratio; Results of Glycemic status and insulinemic status among the study subjects. of were expressed as Mean \pm SD as appropriate' $t$ ' test and Median (range). Mann-Whitney ' $U$ ' test was performed as the test of significance at $5 \%$ significance level. $n=$ number of subjects, $F$ Glu= Fasting glucose; PP_Glu=post prandial ( 2 hours after breakfast) glucose; Ins: Glu=Insulin Glucose ratio; HOMA-B \%= B cell function assessed by homeostasis model assessment. Pearson's correlation analysis were performed. $\mathrm{p}<0.05$ are considered as statistically significant; $n=$ number of subjects. HOMA-B $\%=B$ cell function assessed by homeostasis model assessment and GINR= Glucoseinsulin ratio.

\section{Results}

A total of 153 subjects were included in study of which 63 belonged to insulin resistance T2 DM group and 90 were healthy Controls.

\begin{tabular}{llll}
\multicolumn{4}{l}{ Table I: Anthropometric and Clinical characteristics of the study subjects } \\
Variable & Control $(\mathrm{n}=90)$ & T2DM $(\mathrm{n}=63)$ & P value \\
Age $(\mathrm{Yrs})$ & $46 \pm 8.31$ & $47 \pm 7.58$ & 0.326 \\
BMI $\left(\mathrm{kg} / \mathrm{m}^{2}\right)$ & $24 \pm 3.96$ & $25 \pm 2.72$ & 0.754 \\
WHR & $0.88 \pm 0.06$ & $0.94 \pm 0.12$ & $<0.001$ \\
S_BP $(\mathrm{mmHg})$ & $110 \pm 15.50$ & $117 \pm 16.73$ & 0.008 \\
D_BP $(\mathrm{mmHg})$ & $72 \pm 11.29$ & $78 \pm 9.78$ & 0.003 \\
Glu: Ins & $0.37(0.06-1.52)$ & $0.54(0.17-2.33)$ & $<0.001$
\end{tabular}

Results of Anthropometric and Clinical characteristics of the study subjects were found that Age [(Yrs, Mean \pm SD) $]$ among the Control and type 2 DM subjects were $46 \pm 8.31$ and $47 \pm 7.58$ respectively. There was no significant difference in age between these two groups. The mean BMI $\left[\mathrm{kg} / \mathrm{m}^{2}\right.$, (Mean $\pm \mathrm{SD}$ )], for those who have hypertension (T2 DM, $25 \pm 2.72$ ) and Control, (24 \pm 3.96$)$. Although there was no significantly difference in mean BMI among the study subjects. $(p=0.754)$

The median (range) of the glucose and insulin ratio of the study group were Control 0.37 (0.06 -1.52) and T2DM 0.54 (0.17 - 2.33). There was significant difference in between Control vs. T2DM $(P<0.001)$. Waist-hip ratio $[\mathrm{cm},($ Mean $\pm S D)$ in Control, $0.88 \pm 0.06$ and in T2 DM, $0.94 \pm 0.12]$. There was significantly higher association in T2DM as compared to control subjects $(p<0.001)$. Type 2 DM has significant risk of hypertension S-BP[(Mean \pm SD) in Control, $(110 \pm 15.50)$ and in T2 $\mathrm{DM},(117 \pm 16.13)]$. There was significant in T2DM as compared to control subjects $(p=0.008)$. D-BP[(Mean $\pm S D)$ in Control, $(72 \pm 11.29)$ and in T2 DM, (78 \pm 9.78 .) Significantl association was found in T2DM as compared to control subjects $(p=0.008)$.
Table II: Glycemic status and insulinemic status among the study subjects

$\begin{array}{llll}\text { Variable } & \text { Control }(\mathrm{n}=90) & \text { T2DM }(\mathrm{n}=63) & \text { p value } \\ \text { F_Glu }(\mathrm{mmol} / \mathrm{l}) & 4.96 \pm 0.76 & 8.27 \pm 2.19 & <0.001 \\ \text { PP_Glu }(\mathrm{mmol} / \mathrm{l}) & 5.81 \pm 0.87 & 11.79 \pm 2.69 & <0.001 \\ \text { Glu: Ins } & 0.37(0.06-1.52) & 0.54(0.17-2.33) & <0.001 \\ \text { HOMA-B\% } & 180(59.10-634.50) & 71(4.90-391.30) & <0.001\end{array}$

Results of Glycemic status and insulinemic status among the study subjects were fasting plasma glucose levels [mmol/l, (Mean \pm SD)] of the study group were Control $(4.96 \pm 0.76)$ ) and type $2 \mathrm{DM}$ $(8.27 \pm 2.19)$. There was a significant difference in the fasting plasma glucose between Control vs type2 DM ( $P<0.001)$. (Table 2)

2 hours post prandial plasma glucose level $[\mathrm{mmol} / \mathrm{l}$, (Mean $\pm \mathrm{SD})]$ of the study groups were: Control 5.81 \pm 0.87 and type2 DM $11.79 \pm 2.69$. There was a significant difference in the postprandial plasma glucose between Control vs type2 DM ( $P<0.001)$. The median (range) of the glucose and insulin ratio of the study group were Control 0.37 (0.06 $1.52)$ and T2DM $0.54(0.17-2.33)$. There was significant difference in the postprandial plasma glucose between Control vs. T2DM $(P<0.001)$. The HOMA\%B level median (range) of the study group were Control 180 (59 -634) and type2 DM 71 (4.90 - 391) There was significant difference in between Control vs T2DM $(P<0.001)$. (Table 2)

Table III. Correlation of HOMA\%B with various parameters of the study subjects Variable

\begin{tabular}{llll} 
Control $(n=90)$ & \multicolumn{2}{l}{ T2DM $(n=63)$} \\
$R$ & $P$ & $r$ & $P$ \\
-0.311 & 0.003 & -0.545 & $<0.001$ \\
-0.120 & 0.260 & -0.294 & 0.019 \\
0.591 & $<0.001$ & 0.550 & $<0.001$ \\
0.012 & 0.910 & 0.090 & 0.485 \\
0.068 & 0.524 & 0.071 & 0.578 \\
-0.707 & $<0.001$ & -0.802 & $<0.001$
\end{tabular}

Significant positive correlation were found between HOMA\% B and fasting insulin $(r=0.591, p<0.001)$, and a significant negative association was found with fasting glucose $(r=-0.311, p=0.003)$, GINR $(r=-0.707, p<0.001)$ in the Control group (Table 3).

\section{Discussion}

The capacity for insulin secretion at diagnosis of type 2 diabetes is largely preserved, but the response to cell secretagogues is not equivalent to that seen in nondiabetic subjects. ${ }^{15}$ the insulin secretory defect could be genetically determined as proposed in Kearns-Sayre syndrome ${ }^{16}$, in which there is a decrease in cell mass rather than function. Determination of the contribution of a reduction of cell secretion is complicated by parallel changes in insulin resistance that accompany onset of type 2 diabetes ${ }^{17}$. Assessment of insulin secretion can be made by mathematical modeling (homeostatic model assessment), which indicates that insulin secretion is reduced at the time of diagnosis and further diminishes during the course of the disease. ${ }^{18}$

BMI seems to be a major determinant of insulin secretion in Bangladeshi subjects ${ }^{19}$. In non-diabetic controls (who belonged to normal to overweight BMI range), B-cell function was not affected by BMI as reported in nonobese healthy subjects by Martinez-Abundis et al in a Maxican population ${ }^{20}$. In a Bangladeshi population, nonobese diabetic subjects (BMI of $<25 \mathrm{~kg} / \mathrm{m}^{2}$ ) did not show any hypersecretion 
of insulin. Hyperinsulinemia has been reported in obese nondiabetic Caucasians. These observations reemphasize the importance of body weight in the regulation of peripheral insulin levels and it becomes more and more important in higher degrees of BMI. Hyperinsulinemia is necessary to the hormone secondary to obesity ${ }^{21}$. Insulin secretion ( $\mathrm{HOMA} \% \mathrm{~B})$ was significantly lower in diabetic as compared to control subjects [HOMA\%B, median (range), 71 (4.90 - 391) vs 180 (59-634) $\mathrm{p}<0.001$ ]. (Table 2)

Hyperglycemia (even in a moderate range) appears to be a very sensitive determinant of insulin secretion in T2DM. In contrast to nondiabetic subjects where insulin secretion is linearly related to peripheral glucose, hyperglycemia over a threshold level has a suppressing effect in T2DM ${ }^{22}$. This deleterious effect is often referred to as "glucose toxicity" or "glucose desensitization". The negative impact of glucose has been clearly shown when plasma glucose concentration reach the range associated with diabetes ${ }^{23}$. Asakawa et al have also suggested that diabetic patients with poor glycemic control for a long period show suppressed insulin secretion due to glucotoxicity ${ }^{24}$.

It is interesting to observe that body weight within a range of normal to overweight only BMI representing general obesity was the significant determinant of insulin sensitivity in control and diabetic population. In this range WHR (representing central obesity) was not found to be correlated with any index of insulin sensitivity.

In a cohort studies and clinical trials suggest that higher levels of glucose and insulin may contribute to the development of hypertension independent of obesity and other established hypertension risk factors ${ }^{25}$. Hypertension is a common condition which usually coexists with DM and aggravates DM complications and cardiovascular morbidity and mortality. In our study, both SBP and DBP shows significant association with type $2 \mathrm{DM}$.(S-BP, mean $\pm S D, p=0.003, D-B P$, mean $\pm S D$, $p=0.008$ ).

One reason for the poor prognosis in patients with both diabetes and ischemic heart disease seems to be an enhanced myocardial dysfunction leading to accelerated heart failure due to diabetic cardiomyopathy. ${ }^{26}$

\section{Conclusion}

The type 2 diabetic subjects are at a higher CVD risk as compared to control subjects at comparable levels of biochemical parameters, maintaining BD within normal level and other parameters with type 2 diabetes has dramatic benefits and should be the first priority in diabetes care.

\section{References}

1. Wild S, Roglic G, Green A, Sicree R, King H. Global prevalence of diabetes; estimates for the year 2000 \& projections for2030. Diab. Care; 2004; 27; $1047-53$.

2. Deepa R, Gokulkrishnan K, Mohan V. CAD among Indian diabetic subjects. SASAT 2007.

3. DasUN (2006) Hypertension as a low-grade systemic inflammatory condition that has its origins in the perinatal period. J Assoc Physicians India 54:133-142.

4. Epstein M, Sowers JR. Diabetes mellitus and hypertension. Hypertension 1992;19:403-18.

5. El-Atat F, McFarlane SI, Sowers JR. Diabetes, hypertension, and cardiovascular derangements: pathophysiology and management. Curr Hypertens Rep 2004;6(3): 21523.

6. Sowers JR, Epstein M, Frohlich ED. Diabetes, hypertension, and cardiovascular disease: an update. Hypertension 2001;37(4):1,05359..

7. Adler AI, Stratton IM, Neil AW, Yudkin JS, Matthews DR, Cull CA, et al. Association of systolic blood pressure with macrovascular and microvascular complications of type 2 diabetes (UKPDS 36): prospective observational study. BMJ 2000;321(7,258):41219.

8. Fuller J, Stevens LK, Chaturvedi N, Holloway JF. Antihypertensive therapy for preventing cardiovascular complications in people with diabetes mellitus. Cochrane Database Syst Rev. 2000; (2):CD002188. [PMID: 10796872]

9. Ministry of Health of Morocco. Santé en chiffres 2006-2010...;

10. Tazi MA, Abir-Khalii S, Chaouki N, Cherqaoui S, Lahmouz F, Sraïri JE, Mahjour J. Prevalence of the main cardiovascular risk factors in Morocco: results of a National Survey, 2000. Journal of Hypertension. 2003;21(5):897-903.

11. Hypertension in Diabetes Study (HDS): I. Prevalence of hypertension in newly presenting type 2 diabetic patients and the association with risk factors for cardiovascular and diabetic complications. J Hypertens. 1993;11(3):309-317.

12. Reaven GM. Banting Lecture 1988: Role of insulin resistance in Humandisease. Diabetes; 1988; 37; 1595-1607

13. Haffner SM, Valdez R, Morales PA, Mitchell BD, HazudaHP, Stern MP. Greater effect of glycemia on incidence of Hypertension in women than in men. Diab. Care; 1992; 15(2); 1277-84.

14. El-Atat F, McFarlane S I, Sowers J R, "Diabetes, hypertension, and cardiovascular derangements: pathophysiology and management", Curr. Hypertens. Rep. 2004; 6(3): pp. 215-223.

15. Matthews DR, Cull C, Stratton I, Holman RR, Turner RC: UKPDS 26: sulphonylurea failure in non-insulin dependent diabetic patients over six years. Diabet Med 15:2997-2303, 1997

16. Poulton J, O'Rahilly S, Morten KJ, Clark A: Mitochondrial DNA, diabetes and pancreatic pathology in Kearns-Sayre syndrome. Diabetologia 38:868-871, 1995

17. Turner RC, Holman RR, Matthews DR, Hockaday TD, Peto J: Insulin deficiency and insulin resistance interaction in diabetes: estimation of their relative contribution by feedback analysis from basal plasma insulin and glucose concentrations. Metabolism 28:1086-1096, 1979

18. Matthews DR, Hosker JP, Rudenski A, Turner RC: Homeostatic model assessment (HOMA): measurement of insulin resistance and beta-cell deficit in man. Diabetologia 28:412-419, 1985

19. Zinnat R. Role of insulin deficiency and insulin resistance in the pathogenesis of type2 diabetes mellitus in young Bangladeshi subjects.M Phil Thesis, BIRDEM Academy, University of Dhaka. (1999) pp-57-63

20. Martinez-Abundis E, Grover-Paez MGO (2001). Association of adiposity assessed by means of near infrared interactance with B-cell function, insulin resistance and leptin concentration in non-obese subjects : Ex - ploratory study. J Diab comp 15, 181-184.

21. Wilding JPH (2003) .Obesity and nutritional factors in the pathogenesis of type 2 diabetes mellitus .Textbook of Diabetes Pickup JC and William G.Oxford, Blackwell Science Vol $1,3^{\text {rd }}$ ed, 21.1-21.16.

22. Kahn SE (2003). The relative contributions of insulin resistance and beta cell dysfunction to the pathophysiology of Type 2 diabetes. Diabetologia 46, 3-19.

23. Robertson RP, Olson LK,Zhang HJ (1994). Differentiating glucose toxicity from glucose desensitization : a new message from insulin gene. Diabetes 43, (1085-1089).

24. Asakawa H, Tokunaga K, Kawakami F (2001). Relationship of leptin level with metabolic disorder and hypertention in Japanese type 2 diabetes mellitus patients . J Diab Comp $15,57-62$.

25. Brownlee $M$ The pathobiology of diabetic complications: a unifying mechanism. Diabetes 2005; 54(6): 1615-1625.

26. Rubler S, Dlugash J, Yuceoglu YZ, Kumral T, Branwood AW, Grishman A. New type of cardiomyopathy associated with diabetic glomerulosclerosis. Am J Cardiol. 1972;30:595-602. 